\title{
Prostate Cancer: a comparison of focal therapy and radical prostatectomy
}

\author{
Leonard S. Marks ${ }^{1}$
}

Received: 15 December 2020 / Revised: 21 December 2020 / Accepted: 20 January 2021 / Published online: 28 January 2022

(c) The Author(s), under exclusive licence to Springer Nature Limited 2021

Focal therapy of prostate cancer (PCa) may have been born in the U.S. [1, 2], but it has grown to late adolescence (although not full maturity) in the UK. Early observational studies from University and Imperial Colleges in London have helped make focal therapy a reasonable consideration for many men with PCa $[3,4]$. Now from the UK comes the present study by Shah, Reddy and associates, who compare results of focal therapy and radical prostatectomy. The work does not provide Level 1 evidence, but for now it provides a "next best thing", since attempts to perform a randomized trial (RCT) have failed to recruit.

What the Shah-Reddy study adds is the first meaningful comparison of focal therapy (N-246) vs a standard of care, radical prostatectomy $(N=246)$, in men with mostly intermediate-risk PCa. Methods of focal therapy were highintensity focused ultrasound $(\sim 80 \%)$ and cryoablation $(\sim 20 \%)$. Groups were propensity-matched; data were collected prospectively from centers in the UK $(N=16)$ and Europe $(N=3)$ between 2005 and 2018; and results were compared using the primary outcome of "failure-free survival" (FFS). At eight years of follow-up, some $80 \%$ of each group were failure-free, i.e., had received no additional treatment or developed metastases or died of PCa. When judged by FFS, radical prostatectomy offered no advantage over focal therapy; thus, with this article, focal therapy has gained a measure of credibility in a rightfully skeptical world.

Propensity score matching is a method used by statisticians who, when dealing with observational data, attempt to equalize the effect of known covariates on responses to different treatments. The authors have done an admirable job of putting all the major covariates into their model, and their complicated statistical methods have withstood peer-

Leonard S. Marks

lmarks@mednet.ucla.edu

1 UCLA, Los Angeles, CA, USA review. The results are convincing for what they are, a comparison of the efficacy of the two treatments using a retrospective analysis. Because men have proven unwilling to accept a random assignment to surgery or focal therapy, these data may remain the best available for the indefinite future.

The achievement of the authors in developing this comparison is commendable. However, to cite two of the several limitations: more than one-third of men in each group had Gleason Score $3+3=6$ lesions, which would substantially increase the FFS of each group; today they would likely enter active surveillance. And the success rate for focal therapy (FFS) would have almost certainly been lower than $80 \%$, had success been based on biopsy. Followup biopsies were obtained in less than half of men (personal communication, Taimur Shah), and results are not reported in the article. The study remains in the hypothesisgenerating category.

The real impetus behind focal therapy is the chance of a benefit-and an even better chance of avoiding complications-in situations where treatment is desired, but life is not in immediate danger. Such is the case for many men with intermediate-risk PCa, who are willing to trade cancerspecific survival for improved quality of llfe [5]. For men with intermediate-risk PCa, which is now the commonest cancer found on MR-guided biopsy [6], proving the exact efficacy of focal therapy may be less important than reconfirming its safety.

\section{Compliance with ethical standards}

Conflict of interest Dr. Marks is co-founder Avenda Health.

Publisher's note Springer Nature remains neutral with regard to jurisdictional claims in published maps and institutional affiliations. 


\section{References}

1. Shah TT, Reddy D, Peters M, Ball D, Kim NH, Gomez EG, et al. Focal therapy compared to radical prostatectomy for non-metastatic prostate cancer: a propensity score-matched study. Prostate Cancer Prostatic Dis. 2021;24:567-74.

2. Onik G, Narayan P, Vaughan D, Dineen M, Brunelle R. Focal "nerve-sparing" cryosurgery for treatment of primary prostate cancer: a new approach to preserving potency. Urology. 2002;60:109-14.

3. Ahmed H, Hindley RG, Dickinson L, Freeman A, Kirkham AP, Sahu M, et al. Focal therapy for localixed unifocal and multifocal prostate cancer: a prospective development study. Lancet Oncol. 2012;13:622-32.
4. Guillaumier S, Peters M, Arya M, Afzal N, Charman S, Dudderidge $\mathrm{T}$, et al. A multicenter study of 5-year outcomes following focal therapy in treating clinically significant nonmetastatic prostate cancer. Eur Urol. 2018;74:422-9.

5. Watson V, McCartan N, Krucien N, Abu V, Ikenwilo D, Emberton $\mathrm{M}$, et al. Evaluating the trade-offs men with localized prostate cancer make between the risks and benefits of treatments: the COMPARE study. J Urol. 2020;204:273-80.

6. Chuang R, Kinnaird A, Kwan L, Sisk A, Barsa D, Felker E, et al. Hemi-gland cryoablation of clnically-significant prostate cancer: Intermediate-term follow-up via magnetic resonance imaging guided biopsy. J Urol. 2020;204:941-9. 